\title{
Axial variation of droplet distribution in a venturi scrubber
}

\author{
Â. M. Silva ${ }^{1}$, C. P. Leão ${ }^{1}$, S. F. C. F. Teixeira ${ }^{1}$ \& J. C. F. Teixeira ${ }^{2}$ \\ ${ }^{I}$ Department of Production and Systems, School of Engineering, \\ University of Minho, Portugal \\ ${ }^{2}$ Department of Mechanical Engineering, School of Engineering, \\ University of Minho, Portugal
}

\begin{abstract}
Nowadays, a great effort has been applied into the research of pollution control devices in order to reduce the effect of gaseous emissions to the atmosphere. Amongst the various methods, the venturi scrubber is one of the most efficient processes used for removing dust particles. In this study, droplet dispersion in a large scale circular venturi scrubber, operating horizontally, was examined both theoretically and experimentally. A venturi scrubber was built consisting of a converging section $230 \mathrm{~mm}$ long, a throat of $300 \mathrm{~mm}$ in length and a diverging section $740 \mathrm{~mm}$ in length. The gas velocity at the throat was 34 to $70 \mathrm{~m} / \mathrm{s}$, and the liquid flow rate was set between 0.013 and $0.075 \mathrm{~kg} / \mathrm{s}$. The water is injected just upstream of the venturi and subsequently atomized into droplets of different sizes due to the influence of the turbulent gas stream. Several empirical probability distribution functions have been used to describe the spray distribution. The Rosin-Rammler function, one of the most common distributions, is suited to describe the droplet population. This is handled at each step along the venturi as a distribution of 16 size classes, whose characteristics are based on experimental data. Comparisons between the experimental data and the calculated droplet size are presented.

Keywords: droplets distribution, Rosin-Rammler function distribution, venturi scrubber.
\end{abstract}




\section{Introduction}

Venturi scrubbers are very attractive devices for gas cleaning. They combine a simple and robust construction with high efficiency for small, micron size, particles. Furthermore, they can be used for other purposes such as gas absorption and cooling in a wide variety of industries in order to reduce the emission of lethal gas and particles to the atmosphere.

Their main purpose is to collect the small dust particles into larger droplets which can be subsequently removed by other mechanical devices such as cyclones. Often they are used within other systems.

Liquid droplets are the most important factor for the collection phenomena in the venturi scrubber [1].

Pulley [2] tested the model of Azzopardi et al. [3] against experimental dust collection data and showed that the predictions are sensitive to the value of droplet size used in liquid injected as a spray. However, predictions for the injection of liquid as a film are less sensitive to drop size. If the liquid is atomized into a very fine spray, the surface for particle collection is very high. On the other hand, the efficiency of collection by a single droplet will decrease and droplets will accelerate faster.

Several models for venturi scrubbers have used the correlation developed by Nukiyama and Tanasawa [4] for pneumatic atomizers to specify droplet sizes. Although most models employ a single mean droplet size, others allow the possibility of using a droplet size distribution [5].

In the present work, the model of Cruz [6] is used to model the droplet distribution into a large scale venturi scrubber. Therefore a non uniform droplets concentration distribution is assumed and updated along the venturi taking into account the continuous exchange of liquid between the wavy liquid film on the wall and the gas core. The Rosin-Rammler distribution function is used to describe the droplet population created at each step along the venturi.

\section{Droplet size definition}

Various probability distribution functions (polynomial, Rosin-Rammler, upperlimit root-normal) have been used to describe spray distribution, being the Rosin-Ramler function one of the most common [7].

Alonso et al. [5] reported experimental data in a laboratory-scale venturi and concluded that the Rosin-Rammler distribution function gives good description for the droplet size distribution found in their experiments.

Viswanathan et al. [8] studied two distribution functions, the upper-limit and the root-normal and observed that for all liquid-to-gas ratios, the experimental data are in close agreement with the upper-limit distribution function, both in terms of the shape of the droplet size distribution and the absolute frequency. The root-normal distribution function predicts a higher frequency at peak-value than the experimental data. The measured droplet-size distribution follows the upper-limit distribution function at low throat-gas velocity at $45 \mathrm{~m} / \mathrm{s}$ and the normal distribution is more appropriate at a high gas velocity $(75 \mathrm{~m} / \mathrm{s})$. In 
addition, this probability distribution function is more complex than the RosinRammler, requiring three parameters.

The Rosin-Rammler distribution represents a good compromise in terms of efficiency and in easy of use. It is defined by two parameters and the overall performance is comparable to the one show by the upper limit log normal distribution [9]. This distribution is usually presented by the cumulative weight of droplets:

$$
R R=1-e^{-\left(d_{D} / \bar{x}\right)^{n}}
$$

where $R R$ represents the mass fraction in the particles with a diameter equal or smaller than $d_{D} ; \bar{X}$ and $n$ are the distribution parameters. The $\bar{X}$ is the droplet diameter such that $63,2 \%$ of the total liquid mass is in droplets of smaller diameters and can be related to the Sauter mean diameter $\left(d_{32}\right)$ by means of the gamma function. The parameter $n$ provides a measure of the spread of the distribution [5].

In processes governed by mass and surface phenomena, the Sauter mean diameter $\left(d_{32}\right)$ is often employed to describe the mean diameter of a droplet distribution. This parameter represents the ratio between the volume and the surface area of droplet population:

$$
d_{32}=\frac{\sum_{i=1}^{I}\left(n_{i} d_{i}^{3}\right)}{\sum_{i=1}^{I}\left(n_{i} d_{i}^{2}\right)}
$$

The two parameters in the Rosin-Rammler function and the $d_{32}$ can be used in order to compare the particle size distribution for different positions.

For annular flow in straight tubes, Azzopardi and co-workers developed a $d_{32}$ correlation based on the experiments on tube diameter which demonstrates the dependence of droplet size with gas and liquid flow rates [10]:

$$
\frac{d_{32}}{\lambda}=\frac{15.4}{W e^{0.58}}+\frac{3.5 \rho_{G} W_{L E}}{\rho_{L} W_{G}}
$$

where $\lambda=\sqrt{\sigma / \rho_{L} g}$,We is the Webber number, $W_{L E}$ is the mass flow rate of each droplet class, $\rho_{L}$ is the liquid density and $W_{G}$ is the gas flow rate.

\section{Experimental setup}

Due to the availability of limited measured practical data on droplet sizes in venturi scrubbers (most of the above experiments were conducted in small, laboratory-scale scrubbers) and the limitations of extrapolation data from sources such pneumatic atomizers, detailed droplet-size analysis in venturi scrubbers is rarely found in literature.

Details of the experimental setup used in the present work are presented elsewhere [11]. Only the geometric details of the venturi scrubber are given at Figure 1. The venturi is divided in three sections: convergence (1), throat (2) and 


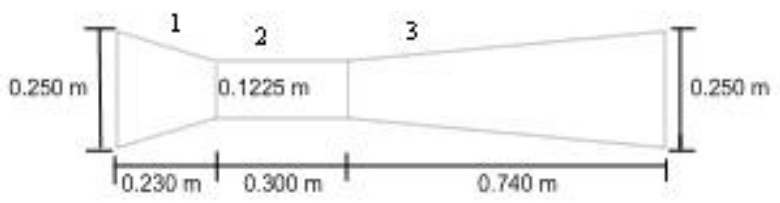

Figure 1: Venturi scrubber geometric details.

divergence (3). It is in the throat section that most of the collection phenomena occur, as well as the break up and coalescence of the droplets.

The technique employed for the droplet size measurements is based upon the Fraunhofer diffraction. When a laser beam strikes droplets/particles, the angular variation of light scattered in the forward direction depends upon the particle size.

If a lens collects the light, that undiffracted is focused in a central spot and that diffracted is projected as a pattern of concentric rings in lens focal plane. Large particles scatter at small angles and small particles scatter at larger angles. Each ring is directly related to the volume fraction of a size in the spray. By using an array of photodetectors, the droplet size distribution can be measured. The results are independent of the velocity. This technique is marketed by Malvern Instruments (Model 2600) and has been widely used in the past [5, 9].

In the present experiments, a $600 \mathrm{~mm}$ focal length lens provided a measurement of droplet size in the range of 11.6-1128 $\mu \mathrm{m}$, which was found to be the most appropriate for the current work.

For each experiment, it is assumed that the droplet sample follows a particular distribution and its parameters are iteratively adjusted to give the best fit. The Rosin-Rammler distribution was chosen among the available alternatives in the system software to allow the comparisons with the numerical results.

The operating parameters tested experimentally are the gas throat velocities $(\mathrm{Vg}=34,52,61$ and $70 \mathrm{~m} / \mathrm{s})$, the liquid flow rates $(0.013$ to $0.075 \mathrm{~kg} / \mathrm{s})$ and the liquid-to-gas ratio, $(\mathrm{L} / \mathrm{G}=0.016$ to $0.187 \mathrm{l} / \mathrm{m} 3)$.

\section{Results}

The pressure drop data and the experimental droplet size from this large scale venturi scrubber are presented in great detail in papers elsewhere for all range of operating conditions $[11,12]$. The theoretical study presented here reports to the gas throat velocity of $52 \mathrm{~m} / \mathrm{s}$ and the liquid flow rate of $0.075 \mathrm{~kg} / \mathrm{s}$.

The droplet distribution used to approximate the droplet size was the RosinRammler (equation 1). The distribution parameters $\bar{X}$ and $n$ considered were fixed and equal to $1.629 \mathrm{~d}_{32}$ and 2.2 , respectively, based on experimental tests [9]. The domain of the droplet size considered in the range of $11.6-1128 \mu \mathrm{m}$ was divided into 16 classes with different amplitude (from 2.2 up to $604.8 \mu \mathrm{m}$ ), which matches the set up of the instrument.

Modelling the exchange between the liquid film on the wall and the gas core (deposition of droplets and entrainment of new liquid from the film), the mass flow rates of the droplets along the venturi can be calculated (Figure 2). 


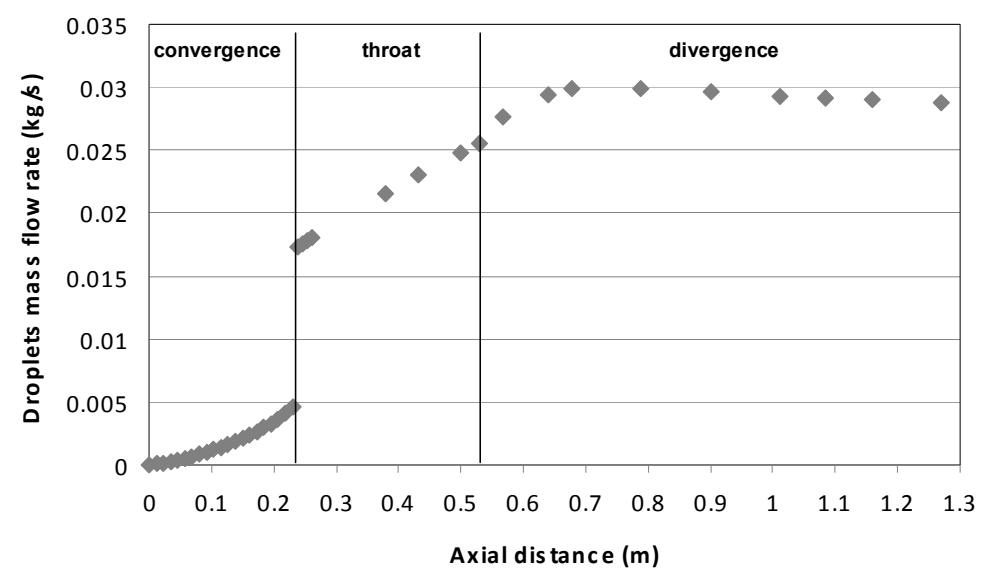

Figure 2: Droplet mass flow rate along the venturi.

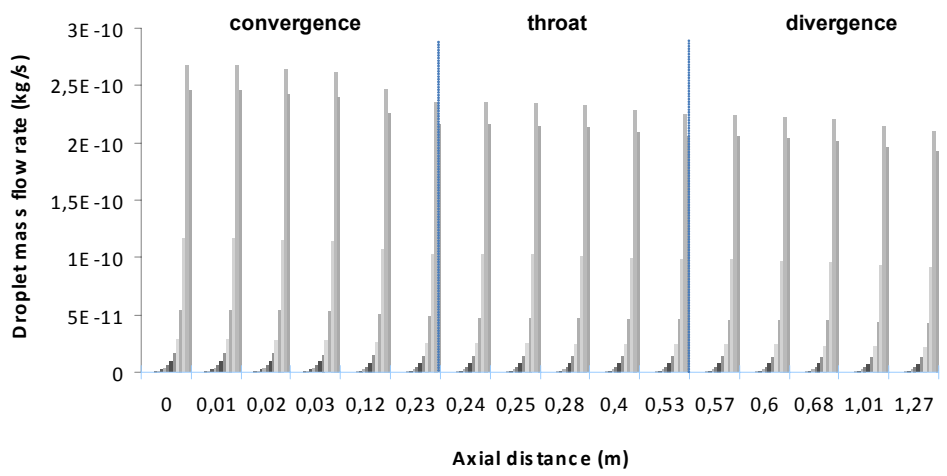

Figure 3: Mass droplet distribution of the first population created at the venturi entrance along the venturi.

The amount of liquid in droplets increases almost linearly throughout the convergence section, up to $0.005 \mathrm{~kg} / \mathrm{s}$. At the beginning of the throat section, an extra entrainment of water occurs followed by a steady increase up to the divergence. In the divergence section, the mass flow rate in droplets is almost constant.

It can be observed that when the water is introduced as a film, just upstream of the venturi, the maximum quantity of water in droplets, correspond, approximately to $50 \%$ of the total liquid flow rate, $0.03 \mathrm{~kg} / \mathrm{s}$.

At each axial position along the venturi, the droplet mass flow rate includes the mass flow rate of the droplet distribution created at that position and the mass flow rate of all droplet distributions created upstream of this point. The $d_{32}$ correlation (equation 3) is used at each position to calculate $\bar{X}$ and $n$, then a new droplet population of 16 size classes distribution is created. The mass flow rate in each size class from the old droplet populations is updated according to the 
deposition rate. In Figure 3, the droplet distribution created at the venturi entrance (first population of droplets) is shown for each position along the venturi. The droplet distribution is similar, only the mass flow rate is lower in each size class.

Figure 4 shows the evolution of the droplets size distribution along the venturi. At each position, the mass flow rates in each size class for all droplet distributions are added up. It is observed that although the increase of the mass flow rate as previously mentioned (Figure 2), the droplet size distribution is different along the venturi. As the droplets moves to the end of the venturi, the distribution tends to the left side, meaning that there exists more water in smaller droplets.

Figure 5 shows the comparisons between the Sauter mean diameter, $d_{32}$ calculated using the equation (2), the Azzopardi correlation (equation 3), along the venturi.

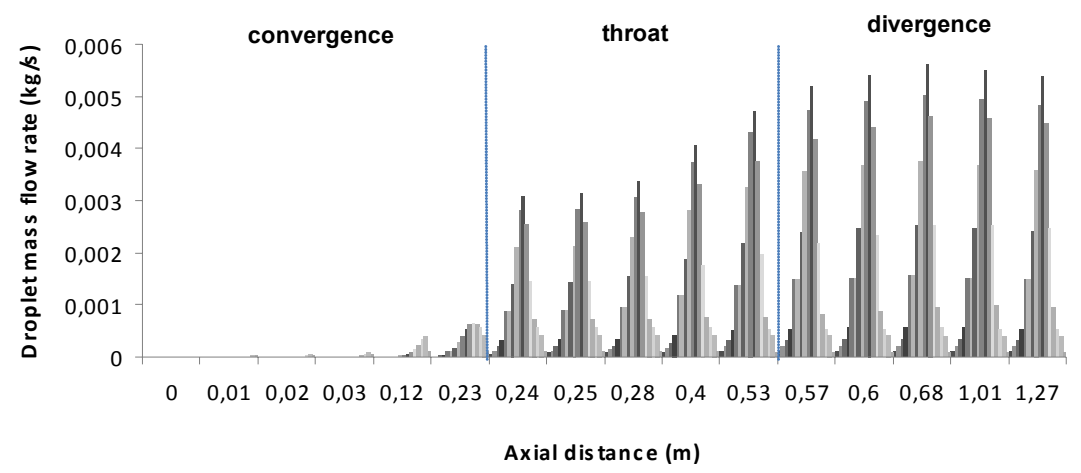

Figure 4: $\quad$ Mass droplets distribution along the venturi.

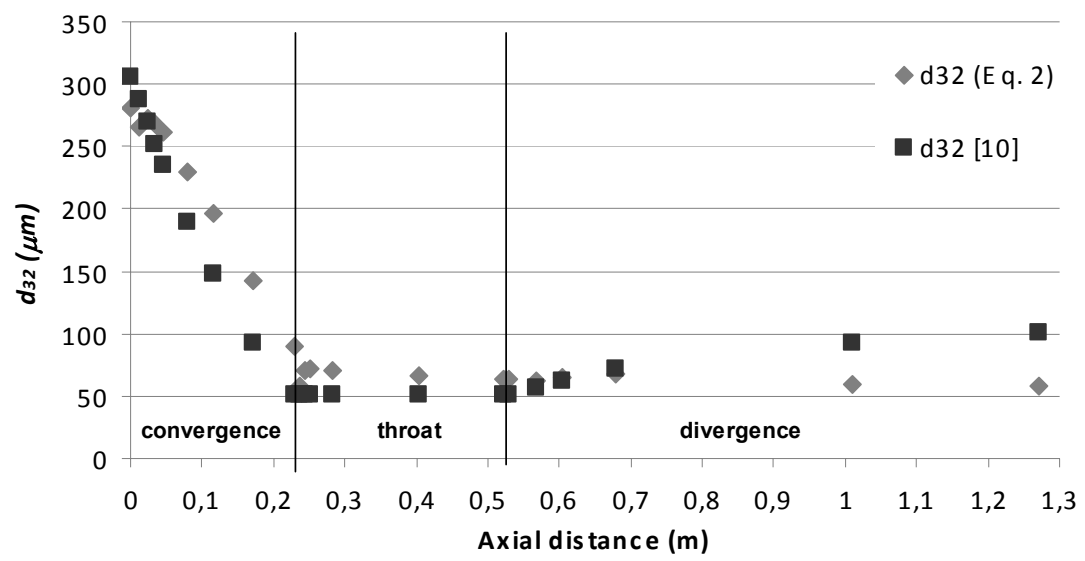

Figure 5: Comparisons between the Sauter mean diameter estimated by definition (Eq. (2)) and the Azzopardi [10] correlation. 
It can be observed that the results present some discrepancies at the convergent section and at the end of the divergent section. This can pointed out the fact that the Azzopardi correlation was obtained from experimental data in straight tubes.

Figure 6 shows the comparisons between the Sauter mean diameters, $d_{32}$ calculated using the equation (2) for the new and the old droplets population and the correlation presented in the equation (3) along the venturi. The old droplets population considers all the droplets unless the new ones created at each point.

The diameters values based on the correlation [10] are similar to the diameters values based only on the new droplets, as expected. These last values were obtained from the distribution generated on the diameter obtained with the correlation. The differences observed are only due to the discretization of the continuous Rosin-Rammler distribution. It is more evident when large sizes are present (Figure 7) because the class amplitude is higher.

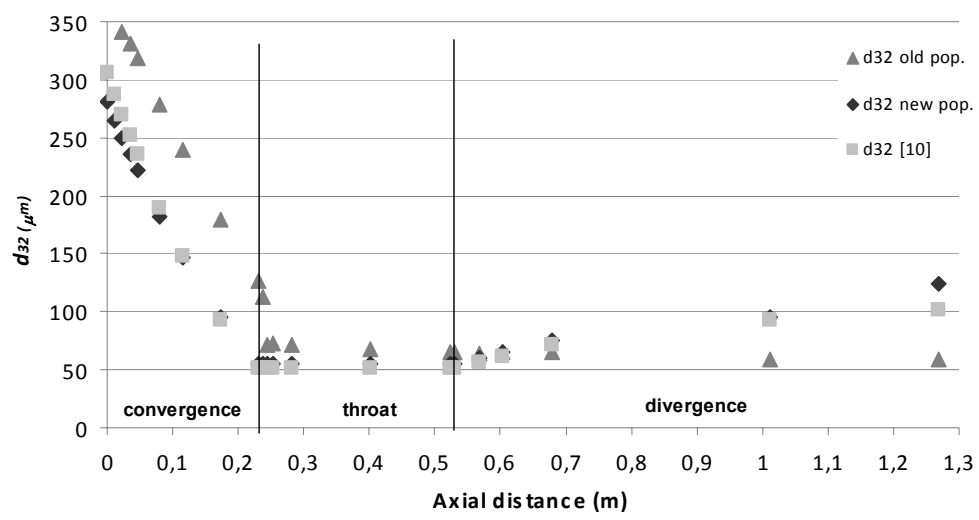

Figure 6: Comparisons between the Sauter mean diameter from different droplet populations (new and old populations) and the Azzopardi [10] correlation.

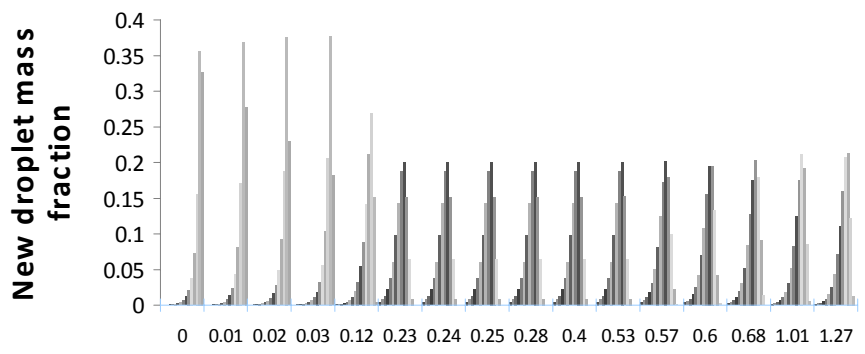

Axial distance $(\mathrm{m})$

Figure 7: Mass fraction distribution of the new classes formed at each axial position. 
The Sauter mean diameter of the old droplets population decrease along the venturi, as expected.

Figure 8 compares the calculated droplet size and the experimental data for the case tested. At the throat section, the flow is not fully developed and so the model based on multiphase flow in a tube does not seem appropriate and some differences are observed, although the trends of the experimental data and the theoretical values are similar.

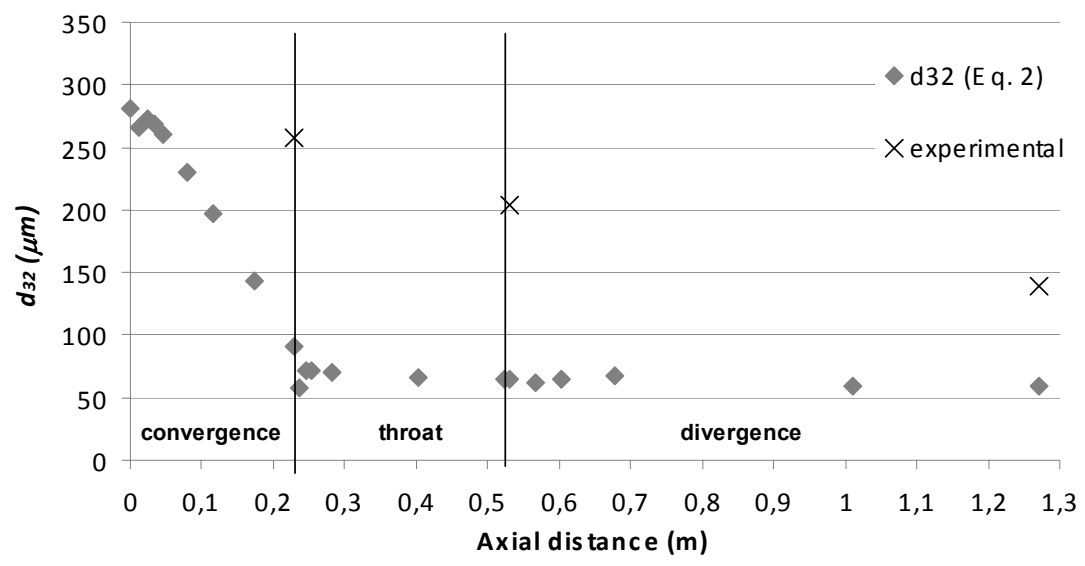

Figure 8: $\quad$ Comparisons of the Sauter mean diameter estimated (Eq.(2)) and the experimental data.

\section{Conclusions}

The Rosin-Rammler function has been used to describe the axial variation of the droplet distribution in a large scale venturi scrubber. The distribution parameters have been calculated using a Sauter mean diameter obtained from a droplet size correlation for tubes. The calculated droplet size follows the experimental data trend although some discrepancies are still observed at the throat region.

\section{References}

[1] T. M. S. Cruz, S. F. C. F. Teixeira and J. C. F. Teixeira, "The role of droplets in scrubbing combustion flue gases", in Proc. of the 4th International Conference on Technologies and Combustion for Clean Environment, (1997) 67-71.

[2] R.A. Pulley, Modelling the performance of venturi scrubber, Chemical Engineering Journal, 67(1997) 9-18.

[3] B.J. Azzopardi, S.F.C.F. Teixeira, A.H. Govan and T.R. Bott, An improved model for pressure drop in venturi scrubbers, Trans. Inst. Chem. Eng., 69 (1991) 55-64. 
[4] S. Nukiyama and Y. Tanasawa, An experiment on the atomisation of liquid by means of air stream. Transactions of the Society of Mechanical Engineers (Japan), 4 (1938) 86-93.

[5] D. F. Alonso, J. A. S. Gonçalves, B. J. Azzopardi and J. R. Coury, Drop Size measurements in venturi scrubbers, Chem. Eng. Sci., 56 (2001) 49014911.

[6] T.M.S. Cruz (1997), Modelação de sistemas de limpeza de gases, Msc Degree Dissertation, University of Minho, Portugal. (In portuguese)

[7] A. H. Lefevre, Atomization and cloud behaviour in venturi scrubbing, J. Air Pollution Control Assoc., 23(1989) 600-604.

[8] S. Viswanathan, D. S. Lim and M. B. Ray, Measurement of drop size and distribution in an annular two-phase, two-component flow occurring in a venturi scrubber, Ind. Eng. Chem. Res., 44(2005) 7458-7468.

[9] J.C.F. Teixeira (1988), Turbulence in annular two-phase flow, PhD Thesis, University of Birmingham.

[10] B. J. Azzopardi, A. H. Govan, The modelling of venturi scrubbers, Filtr. Sep. 21(3) (1984), 196-200.

[11] A. M. Silva, J.C.F. Teixeira and S.F.C.F. Teixeira "Experiments in large scale venturi scrubber Part I: Pressure Drop", Chemical Engineering and Processing (in press).

[12] A. M. Silva, J.C.F. Teixeira and S.F.C.F. Teixeira, "Experiments in large scale venturi scrubber Part II: Droplet Size", Submitted to Chemical Engineering and Processing. 